\title{
Antitrust issues in scholarly and legal publishing \\ Report on an invitational symposium in Washington, D.C.
}

O

n February 11, 2005, more than 50 lawyers and law professors, antitrust experts, federal and state regulators, economists, professors, librarians, and international delegates gathered in Washington, D.C., at the Georgetown Law School to explore issues surrounding the scholarly and legal publishing industry. Cosponsored by the Information Access Alliance (IAA) and the American Antitrust Institute (AAI), the symposium grew out of shared concern about unconstrained publisher mergers, the increasing concentration of the scientific and legal journal content in the hands of a few publishers, and the effects of bundling and price escalation on universities and libraries.

Presenters in the daylong seminar included well-known economists, lawyers and librarians-a virtual who's who of experts who, for more than a decade, have helped to shape our understanding of the business of scholarly journals and their spiraling costs. The majority of participants were not librarians, which made the lively and informed discussions about "our" issues-bundling, journal costs, and publisher mergers-all the more remarkable. By the end of the day, it was clear that librarians have impressive allies whose interests in addressing the problems with this market match our own.

What follows is a summary of the presentations, with emphasis on the viewpoints that might be less familiar to even well-informed academic librarians and on some of the more provocative ideas that were floated and discussed throughout the day.

\section{The state of the market}

Ted Bergstrom is professor of Economics at the University of California-Santa Barbara. He and his son Carl have studied the "Peculiar Market for Academic Journals" for years, producing some of the most impressive statistics to be found on the cost of journals. His data supported his theme-that nonprofit publishers produce most of the citations, while the for-profit publishers collect most of the money. Bergstrom identified three pricing strategies that resulted from the emergence of electronic journals: price discrimination by the size of the university, bundling of content with all-or-nothing pricing, and consortium pricing. He believes that the author-pays open-access model is more competitive than the consumer-pays model because he believes that authors will shop around for the best price, forcing publishers to keep author charges competitive.

Central to the day's discussions was the contribution of publisher mergers to industry dysfunction. Mary Case, university librarian at the University of Illinois-Chicago, charted recent publisher mergers, some of which were challenged at the Department of Justice (DOJ) by the Association of Research Libraries (ARL) and IAA. Because DOJ has tended to focus on relatively narrow definitions of market overlap, it often addresses

Lee C. Van Orsdel is dean of Libraries at Eastern Kentucky University, e-mail: lee.vanorsde@eku.edu

(c) 2005 Lee C. Van Orsdel 
antitrust concerns by requiring the merging companies to divest certain assets, like journals that have similar content. Too often the divestiture drives titles right into the stables of other high-priced publishers, exacerbating the problem rather than mitigating it. Case presented data that ties mergers to accelerated journal price increases - a cause and effect relationship that is crystal clear to librarians. Antitrust regulators, however, have failed to stop mergers within the science, technical, and medical (STM) and legal publishing markets precisely because they don't find the data convincing.

The difficulty is that we don't yet have the kind of data that would prove the connection between mergers and price escalation to the level required by antitrust law. That problem was visited and discussed repeatedly throughout the day. Two attorneys from the Antitrust Division of the DOJ were participants, and their comments provided particularly useful insights into the workings of the Antitrust Division and the hurdles we face in trying to apply antitrust standards to this market.

James Neal, vice president for information services and university librarian at Columbia University, spoke to the economic behavior of libraries, strained on all fronts by the shift from print to electronic, from set prices to negotiated prices, from purchasing content to purchasing both content and database management software, from local collection development to collection development by consortia or by publisher-defined bundles. He observed that librarians have a hard time walking away from the negotiating table even when the deals aren't reasonable, and implicated that librarians must cultivate their ability to send market signals that force publishers to moderate their prices and practices.

\section{Market economics}

Mark McCabe, professor at Georgia Institute of Technology and former DOJ economist, has done substantial research on the buying patterns of libraries (in a nutshell: buy all the journals we can, try not to cancel subscriptions). His research attempts to connect those patterns (which he calls "library portfolio behavior") with publisher pricing behaviors and with their strategy of acquiring ever more content, which drives the mergers we are seeing. He finds a clear correlation between mergers and journal price increases in excess of already high rates of inflation. His analysis of the industry is complicated and difficult to understand if you are not an economist, but his data is persuasive and has become foundational to the work of others who are trying to define the problem with the STM and legal publishing market in terms that would justify antitrust action.

Dan Rubinfeld, professor of law at the University of California-Berkeley, characterized bundling as a strategy publishers use to address the increasing elasticity (i.e., cancellations) in the journals market following the advent of electronic formats. From an economic point of view, bundling is a legitimate strategy, but in certain circumstances it can be viewed as anticompetitive. Rubinfeld ran a textbook analysis of the two sections of the Sherman Act to determine whether either section could be applied to the bundling practices of an STM publisher. Using Elsevier's Science Direct as case in point, he considered whether their Big Deals restrained trade according to section 1 of the Sherman Act. He concluded it was a hard case to make. He thinks the better case could be made using section 2 of the act, which looks for unilateral or monopolistic practices that create barriers to entry for other competitors. One difficulty in making that case is the lack of good data about library budgets and the effects of bundling on their ability to purchase other journals of equal quality. Rubinfeld closed with an admonition to librarians which echoed that of James Neal earlier: to wit, librarians must make publishers understand that libraries will say no when publishers fail to put reasonable deals on the table.

One of the most provocative questions of the day focused on the issue of restraint of trade and what, if any, actions libraries can take jointly. Asked if a group of ARL libraries could decide as a group to cancel all of the 
journals from those publishers whose pricing practices were unacceptable, the resounding answer from this room full of economists and lawyers was 'No-it would be illegal." Asked if it would be legal to articulate principles and deal only with publishers who adhered to those principles, the answer was to "get legal counsel." At the end of the symposium one attorney offered to draft some guidelines describing what libraries can legally do to signal displeasure with the market.

\section{Legal and market remedies}

Bert Foer, AAI president, delivered an insightful overview of merger law in the context of the STM journal market. He noted that rampant mergers, abnormal price increases, the rapid uptake of the Internet as a delivery system, and bundling (or tying, as it is known in antitrust parlance) are characteristics that tend to trigger the interest of antitrust attorneys in any market.

Regarding mergers, Foer sees market definition as the crucial issue. Because the DOJ defines the publishing market broadly, it is difficult to prove that STM publishers have the kind of concentration that typically characterizes a monopolistic market. For example, DOJ includes nonprofit publishers in the market because they are competitors with commercial publishers. Foer feels that a more constructive analysis might involve content segments, like chemistry or molecular biology, where concentration would be more apparent. He reiterated that prices and bundling are other good reasons to look at this market as anticompetitive.

It is clear to him that STM publishers have the power to limit buyer choice, which antitrust law is supposed to protect. He believes that bundling is driving mergers and that the mergers will continue. He recognizes the difficulty in connecting these theoretical observations with antitrust strategies, but he clearly sees the urgency for doing so.

Rick Johnson, director of SPARC (the Scholarly Publishing and Academic Resources Coalition), discussed the role of open-access publishing as a legitimate market remedy that promises to reduce the pricing power of publishers, remove unnecessary barriers to access, and introduce efficiencies by unbundling the functions associated with scholarly publishing. He reviewed the principles of open-access publishing and some of the business practices associated with open-access journals, stressing that the two things are distinct and separate. Despite the promise of these remedies, the market remains gridlocked in contention over who and what will change. Johnson makes a good case for viewing open access as a public policy issue, which gives the need for changes to the system a larger context and a legitimate urgency.

In his second presentation at the end of the day, Rubinfeld focused on antitrust remedies and strategies for change. He chastised scholarly societies, many of whom he believes are too timid to take a stance on these issues. He believes societies have to recognize their social responsibility to disseminate research (presumably giving that precedence over other goals, such as making money for the society). He also pointed out that all states have consumer protection laws to protect susceptible populations. Rubinfeld believes that state attorneys general are the logical ones to pursue protection from publisher strategies that constrain access because they don't have the burden of proof associated with antitrust litigation.

The assumption here appeared to be that publicly funded institutions and their libraries have become victims of the current market and need the protection of the state. There is also the argument that states should protect their assets in the form of scholarly outputs created via public funding. In effect, a state can lose access to its own outputs when content is given to publishers who exploit it to the point that libraries in the state can't afford to purchase it back.

\section{Developing strategies}

The final hour was devoted to identifying "next steps." Led by Tom Susman, partner in Ropes and Gray (counsel for IAA), focus 
groups were formed that reflected the diversity of expertise represented in the symposium. Each group addressed the following questions: What additional research is needed? What do we need to do to entice DOJ to take a closer look at the issues raised? How do we get state attorneys general involved? What can libraries do to make demand more elastic? The list of strategies, when compiled, was quite long. But the energy and commitment in the room at the end of the day was palpable. The session closed with a pledge from Robert Oakley-our host, moderator, and director of the Law Library at Georgetown University - that the work of the group was just beginning.

\section{Symposium sponsors}

IAA is an advocacy organization formed by the Association of Research Libraries, ALA, ACRL, the American Association of Law Libraries, the Medical Library Association, the Special Library Association and SPARC, with the specific intent to build a network of influential spokespersons outside of the academy who would work with the IAA to effect change on public policy, antitrust regulation, or publisher behaviors that put the open exchange of information at risk. ${ }^{1}$

The American Antitrust Institute is an independent, nonprofit research, education, and advocacy organization with the mission of increasing the role of fair and effective competition in markets and challenging the abuses of concentrated economic power in the American and world economies. They believe that competition is an essential element of civil society, and their work is supported by foundations, law firms, corporations, associations, and individuals.

\section{Note}

1. Mary Case, "Information Access Alliance: Challenging anticompetitive behavior in academic publishing," CERL News (June 2004): 310-313. 2

\section{Elegant Solutions for Preservation}

call for a complete catag

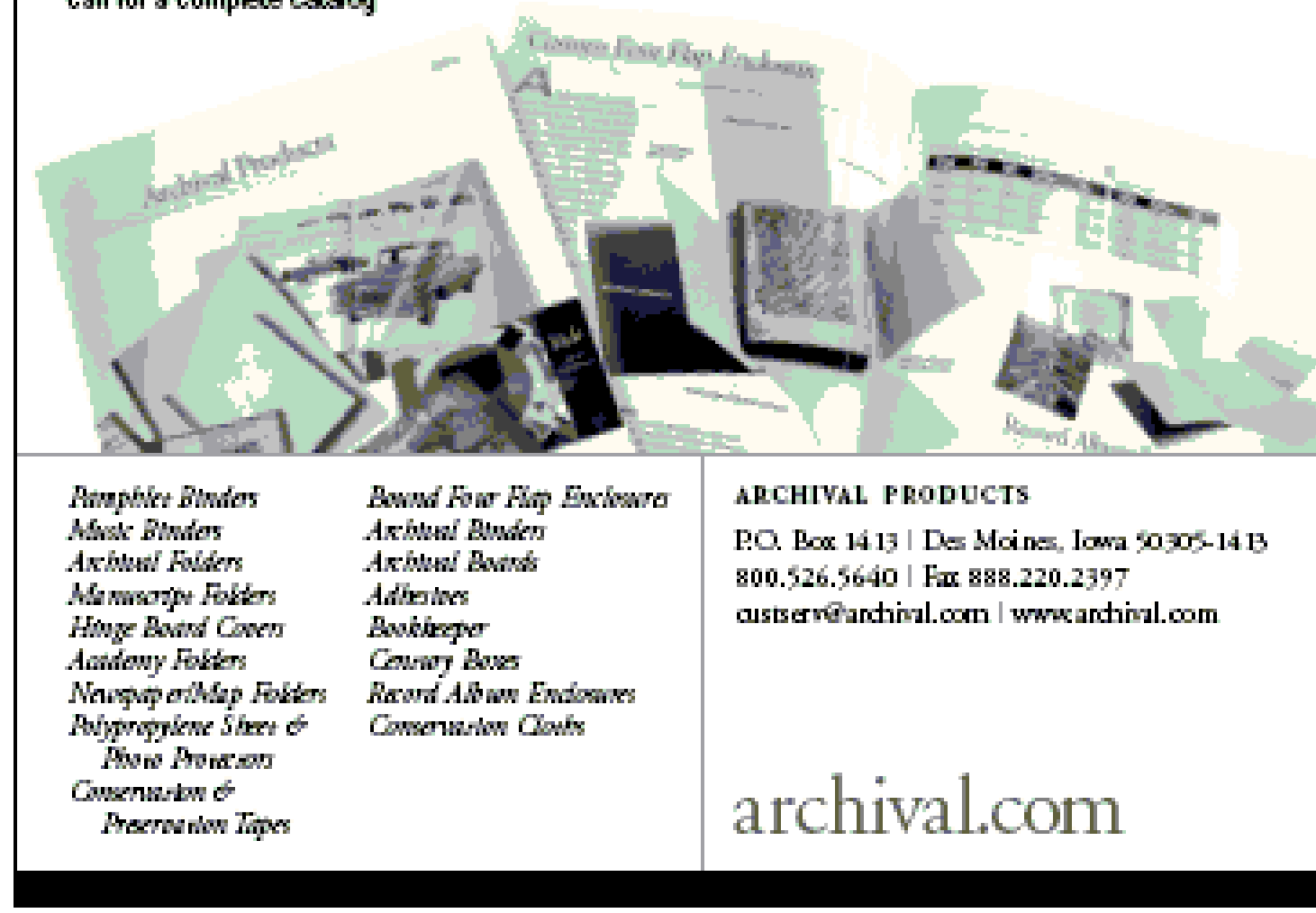

